\title{
Direct oral anticoagulants: key considerations for use to prevent stroke in patients with nonvalvular atrial fibrillation
}

This article was published in the following Dove Press journal:

Vascular Health and Risk Management

10 June 2015

Number of times this article has been viewed

Jerome Ment

Department of Cardiology,

Birmingham Heartlands Hospital, Birmingham, UK
Correspondence: Jerome Ment Department of Cardiology, Birmingham Heartlands Hospital, Bordesley Green East, Bordesley Green, Birmingham, West Midlands B9 5SS, UK

Tel +44 I II 4240744

Fax +44 I 2 I 424 I074

Email jerome.ment@heartofengland.nhs. uk
Abstract: Atrial fibrillation (AF) is the most common cardiac arrhythmia worldwide. Strokes that occur as a complication of AF are usually more severe and associated with a higher disability or morbidity and mortality rate compared with non-AF-related strokes. The risk of stroke in $\mathrm{AF}$ is dependent on several risk factors; $\mathrm{AF}$ itself acts as an independent risk factor for stroke. The combination of effective anticoagulation therapy, risk stratification (based on stroke risk scores, such as $\mathrm{CHADS}_{2}$ and $\mathrm{CHA}_{2} \mathrm{DS}_{2}$-VASc), and recommendations provided by guidelines is essential for decreasing the risk of stroke in patients with AF. Although effective in preventing the occurrence of stroke, vitamin K antagonists (VKAs; eg, warfarin) are associated with several limitations. Therefore, direct oral anticoagulants, such as apixaban, dabigatran etexilate, edoxaban, and rivaroxaban, have emerged as an alternative to the VKAs for stroke prevention in patients with nonvalvular AF. Compared with the VKAs, these agents have more favorable pharmacological characteristics and, unlike the VKAs, they are given at fixed doses without the need for routine coagulation monitoring. It remains important that physicians use these direct oral anticoagulants responsibly to ensure optimal safety and effectiveness. This article provides an overview of the existing data on the direct oral anticoagulants, focusing on management protocols for aiding physicians to optimize anticoagulant therapy in patients with nonvalvular AF, particularly in special patient populations (eg, those with renal impairment) and other specific clinical situations.

Keywords: direct oral anticoagulants, nonvalvular atrial fibrillation, rivaroxaban, stroke prevention, warfarin

\section{Introduction}

Atrial fibrillation (AF) is associated with substantial morbidity and mortality, mainly owing to the potential for thrombus formation and emboli that may occlude cerebral vessels. ${ }^{1,2}$ Based on data from a large European population-based study, the overall prevalence of $\mathrm{AF}$ is $5.5 \%$; prevalence increases with age, rising from $0.7 \%$ in people aged $55-60$ years to $17.8 \%$ in those aged $\geq 85$ years. ${ }^{3}$ Because it is predominantly a disease of the elderly, the overall prevalence of AF is predicted to more than double by 2050 , driven by the aging population. ${ }^{3-5}$

Approximately $15 \%$ of all strokes are associated with AF, and patients with $\mathrm{AF}$ have an approximately fivefold increase in the incidence of stroke compared with patients without AF. ${ }^{1,2}$ Furthermore, strokes that occur in patients with AF are more severe than those in patients without $\mathrm{AF}$, as demonstrated by the higher rates of death and the greater functional deficit associated with AF-related stroke. ${ }^{6,7}$

Optimal risk stratification plays a key role in the identification of patients with nonvalvular AF who have an elevated risk of stroke and would benefit from 
anticoagulant therapy. Factors associated with increased risk of stroke include prior thromboembolism, age $\geq 65$ years, hypertension, congestive heart failure, impaired left ventricular systolic function, diabetes, female sex, and prior myocardial infarction (MI). ${ }^{8-11}$ Several stroke risk scores exist: the most commonly used are $\mathrm{CHADS}_{2}$ (Congestive heart failure, Hypertension, Age, Diabetes, and Stroke or transient ischemic attack [TIA] previous event [2 points]) and $\mathrm{CHA}_{2} \mathrm{DS}_{2}$-VASc (Congestive heart failure/left ventricular dysfunction, Hypertension, Age $\geq 75$ years [2 points], Diabetes, Stroke or TIA previous event/thromboembolism [2 points], Vascular disease, Age 65-74 years, and Sex category [female]). The latter score was developed from the former to take into account important risk factors such as vascular disease, age, and sex (Table 1). ${ }^{10,12,13}$

To reduce the likelihood of stroke, oral anticoagulant therapy is recommended in all patients with AF who have additional stroke risk factors. A recent epidemiological study looking at anticoagulant use in patients with AF concluded that just $16 \%$ had no associated risk factors (ie, had a $\mathrm{CHADS}_{2}$ score of 0$) .{ }^{14}$ This suggests that most patients with AF should be considered for anticoagulation; however, more than one-third of eligible patients received no form of anticoagulation. ${ }^{14}$ The vitamin $\mathrm{K}$ antagonists (VKAs) are substantially more effective than antiplatelet therapy for stroke prevention: data from nine randomized trials comparing VKAs with acetylsalicylic acid (ASA) in patients with nonvalvular AF showed that VKAs were significantly more effective in preventing stroke (39\% relative risk reduction). ${ }^{15,16}$ Even in an elderly cohort ( $\geq 75$ years of age), warfarin resulted in a significantly lower number of strokes with no appreciable increase in bleeding rates compared with ASA (1.4\% with warfarin versus $1.6 \%$ with ASA). ${ }^{17} \mathrm{VKA}$ therapy has also been shown to have greater efficacy than dual antiplatelet therapy (DAPT; ASA plus clopidogrel) for stroke prevention in high-risk patients with AF (72\% risk reduction) without a significant increase in major bleeding. ${ }^{18}$ Therefore, the European Society of Cardiology (ESC) 2012 updated guidelines advise that treatment with ASA and clopidogrel should be reserved for patients in whom warfarin is considered unsuitable. ${ }^{8}$

Although the efficacy of VKAs for stroke reduction in patients with AF is well established, ${ }^{16}$ these anticoagulants have several limitations, including a slow onset of action, a narrow therapeutic window, a high variability in dose response (influenced by patients' genetic background and other factors), numerous food and drug interactions, and the need for frequent coagulation monitoring and dose adjustment. ${ }^{19-21}$ As a result, it is challenging to use VKAs in clinical practice, prompting the development of direct oral anticoagulants.

The direct oral anticoagulants include the direct Factor $\mathrm{Xa}$ inhibitors apixaban, edoxaban, and rivaroxaban, and the direct thrombin inhibitor dabigatran, all of which can be administered as fixed doses, delivering predictable anticoagulation. $^{22}$ Apixaban, rivaroxaban, and dabigatran have been approved in Europe and the US for stroke prevention in AF, treatment of deep vein thrombosis and pulmonary embolism, and prevention of recurrent venous thromboembolism (VTE). ${ }^{23-25}$ Dabigatran is approved in Europe, and

Table I $\mathrm{CHADS}_{2}$ and $\mathrm{CHA}_{2} \mathrm{DS}_{2}$-VASc stroke risk scoring systems and adjusted stroke rates based on $\mathrm{CHADS}_{2}$ and $\mathrm{CHA}_{2} \mathrm{DS}_{2}-\mathrm{VASC}$ scores

\begin{tabular}{|c|c|c|c|c|c|c|}
\hline & \multicolumn{2}{|c|}{ Stroke risk scoring systems } & \multicolumn{2}{|c|}{$\begin{array}{l}\text { Adjusted stroke rate based } \\
\text { on } \mathrm{CHADS}_{2} \text { score }\end{array}$} & \multicolumn{2}{|c|}{$\begin{array}{l}\text { Adjusted stroke rate based } \\
\text { on } \mathrm{CHA}_{2} \mathrm{DS}_{2} \text {-VASc score }\end{array}$} \\
\hline & $\begin{array}{l}\text { CHADS }_{2} \text { scoring } \\
\text { system }\end{array}$ & $\begin{array}{l}\mathrm{CHA}_{2} \mathrm{DS}_{2} \text {-VASc } \\
\text { scoring system }\end{array}$ & $\begin{array}{l}\text { CHADS }_{2} \\
\text { score }\end{array}$ & $\begin{array}{l}\text { Adjusted stroke } \\
\text { rate (\%/year) }\end{array}$ & $\begin{array}{l}\mathrm{CHA}_{2} \mathrm{DS}_{2} \text {-VASc } \\
\text { score }\end{array}$ & $\begin{array}{l}\text { Adjusted stroke } \\
\text { rate (\%/year) }\end{array}$ \\
\hline Congestive heart failure & I & I & 0 & 1.9 & 0 & 0 \\
\hline Hypertension & 1 & 1 & 1 & 2.8 & 1 & 1.3 \\
\hline Age $\geq 75$ years & I & 2 & 2 & 4.0 & 2 & 2.2 \\
\hline Diabetes & I & I & 3 & 5.9 & 3 & 3.2 \\
\hline Previous stroke or TIA & 2 & 2 & 4 & 8.5 & 4 & 4.0 \\
\hline Vascular disease & - & I & 5 & 12.5 & 5 & 6.7 \\
\hline Age, $65-74$ years & - & I & 6 & 18.2 & 6 & 9.8 \\
\hline Female sex & - & 1 & - & - & 7 & 9.6 \\
\hline \multirow[t]{2}{*}{ Maximum score } & 6 & 9 & - & - & 8 & 6.7 \\
\hline & - & - & - & - & 9 & 15.2 \\
\hline
\end{tabular}

Note: Data from Gage et al, ${ }^{10,12}$ Lip et al, ${ }^{13}$ and Camm et al. ${ }^{15}$

Abbreviations: $\mathrm{CHADS}_{2}$, Congestive heart failure, Hypertension, Age $\geq 75$ years, Diabetes mellitus, and Stroke or TIA previous event (2 points); CHA DS 2 -VASc, Congestive heart failure/left ventricular dysfunction, Hypertension, Age $\geq 75$ years ( 2 points), Diabetes, Stroke or TIA previous event/thromboembolism ( 2 points), Vascular disease, Age 65-74 years, and Sex category (female); TIA, transient ischemic attack. 
rivaroxaban and apixaban are approved in both Europe and the US for the prevention of VTE after elective hip or knee replacement surgery. ${ }^{23-25}$ Rivaroxaban, co-administered with ASA alone or with ASA plus clopidogrel or ticlopidine, is additionally approved in Europe for the prevention of atherothrombotic events in adult patients after an acute coronary syndrome (ACS) event with elevated cardiac biomarkers. ${ }^{25}$ At present, edoxaban is approved in Japan (in several indications) and in the US for the prevention of stroke in patients with nonvalvular AF and for the treatment of VTE; ${ }^{26}$ it is also under review by the European Medicines Agency (EMA) for approval in Europe.

This review will summarize the current treatment options and recommendations for the prevention of stroke in patients with nonvalvular AF, with an emphasis on the direct oral anticoagulants, highlighting important considerations regarding their use in high-risk patients and offering practical advice for clinical scenarios often encountered by the practicing physician.

\section{Anticoagulation and stroke prevention}

Current guidelines recommend anticoagulants over other antiplatelet therapies for the prevention of stroke in patients with AF with one or more risk factors. ${ }^{8,9,15,27}$ The pivotal clinical studies of the direct oral anticoagulants for stroke prevention in patients with AF are presented below, along with the relevant properties of these agents.

\section{Apixaban, dabigatran, edoxaban, and rivaroxaban for stroke prevention in nonvalvular atrial fibrillation Pharmacodynamic and pharmacokinetic properties} The pharmacological profiles of the direct oral anticoagulants are more favorable than those of VKAs, such as warfarin. These novel agents target a single clotting factor (Factor Xa [apixaban, edoxaban, and rivaroxaban] or thrombin [dabigatran]) and, compared with warfarin, they have a faster onset of action (time to peak concentration: $0.5-4$ hours versus 36-72 hours), shorter half-lives (5-17 hours versus 20-60 hours), and considerably fewer food and drug interactions (Table 2). ${ }^{28-31}$ Therefore, these agents can be administered at fixed doses without a need for routine coagulation monitoring. ${ }^{19,20}$

Efficacy and safety in Phase III clinical studies

Large Phase III studies have investigated the efficacy and safety of apixaban, dabigatran, edoxaban, and rivaroxaban, compared with warfarin or ASA, in patients with nonvalvular AF. These include ARISTOTLE (Apixaban for Reduction In STroke and Other ThromboemboLic Events in atrial fibrillation), AVERROES (Apixaban VERsus acetylsalicylic acid to pRevent stroke in atrial fibrillation patients who

Table 2 Characteristics of direct oral anticoagulants compared with those of warfarin

\begin{tabular}{|c|c|c|c|c|c|}
\hline Characteristics & Warfarin & Apixaban & Dabigatran & Rivaroxaban & Edoxaban \\
\hline Bioavailability & $>95 \%$ & $\begin{array}{l}\sim 50 \% \text { for doses up } \\
\text { to } 10 \mathrm{mg}\end{array}$ & $\sim 7 \%$ & $\begin{array}{l}>80 \% \text { for } 10 \mathrm{mg} \text { dose (regardless } \\
\text { of food intake) and } 20 \mathrm{mg} \text { dose } \\
\text { (taken with food); } 66 \% \text { for } 20 \mathrm{mg} \\
\text { dose (under fasting conditions) }\end{array}$ & $\sim 62 \%$ for $60 \mathrm{mg}$ dose \\
\hline Time to peak activity & 24-36 hours & 3-4 hours & $0.5-2$ hours & $2.0-4$ hours & $\begin{array}{l}\mathrm{I}-2 \text { hours for } \\
10-150 \mathrm{mg} \text { single dose }\end{array}$ \\
\hline Half-life & $20-60$ hours & $\sim 12$ hours & II-I4 hours & $\begin{array}{l}\text { 5-9 hours (young individuals); } \\
\text { II-I3 hours (elderly individuals) }\end{array}$ & $\begin{array}{l}6-11 \text { hours for } \\
10-150 \mathrm{mg} \text { single dose }\end{array}$ \\
\hline Dosing frequency in AF & Once daily & Twice daily & Twice daily & Once daily & Once daily \\
\hline Drug interactions & $\begin{array}{l}\text { Numerous drugs } \\
\text { including substrates of } \\
\text { CYP2C9, CYP3A4, and } \\
\text { CYPIA2; various foods }\end{array}$ & $\begin{array}{l}\text { Strong inhibitors/ } \\
\text { inducers of both } \\
\text { CYP3A4 and P-gP }\end{array}$ & $\begin{array}{l}\text { Strong P-gP } \\
\text { inhibitors and } \\
\text { inducers }\end{array}$ & $\begin{array}{l}\text { Strong inhibitors of both } \\
\text { CYP3A4 and P-gp; strong } \\
\text { CYP3A4 inducers }\end{array}$ & Strong P-gP inhibitors \\
\hline Renal elimination & $<1 \%$ & $\sim 27 \%$ & $85 \%$ & $\begin{array}{l}66 \% \text { of the dose undergoes } \\
\text { metabolic degradation, with half } \\
\text { then being eliminated renally } \\
\text { and the other half eliminated } \\
\text { via the hepatobiliary route. } \\
\text { The final } 33 \% \text { of the dose } \\
\text { undergoes direct renal excretion }\end{array}$ & $\sim 50 \%$ \\
\hline
\end{tabular}

Note: Data from Bristol-Myers Squibb, Pfizer, ${ }^{23}$ Boehringer Ingelheim International GmbH, ${ }^{24}$ Bayer Pharma AG, ${ }^{25}$ Daiichi Sankyo Inc., ${ }^{26}$ Eriksson et al, ${ }^{28} \mathrm{Harder},{ }^{30}$ Verma and Brighton, ${ }^{31}$ Stampfuss et al, ${ }^{94}$ Matsushima et al, ${ }^{95}$ and Mendell et al. ${ }^{96}$ Abbreviations: AF, atrial fibrillation; CYP, cytochrome P450; P-gP, P-glycoprotein. 
have failed Or are unsuitable for vitamin $\mathrm{K}$ antagoniSt treatment), RE-LY (Randomized Evaluation of Long-term anticoagulation therapY), ENGAGE AF-TIMI 48 (Effective Anticoagulation With Factor Xa Next Generation in Atrial Fibrillation-Thrombolysis In Myocardial Infarction Study 48), and ROCKET AF (Rivaroxaban Once daily, oral, direct factor Xa inhibition Compared with vitamin $\mathrm{K}$ antagonism for prevention of stroke and Embolism Trial in Atrial Fibrillation). ${ }^{32-36}$ The design and main efficacy and safety outcomes of these studies are shown in Table 3. No head-to-head comparison trials of the direct oral anticoagulants have been conducted to date.

In the studies comparing the direct oral anticoagulants with warfarin, high-dose dabigatran (150 mg twice daily [bid]), and apixaban were shown to be superior to warfarin for the prevention of stroke and systemic embolism in the intention-to-treat population; ${ }^{32,34,37}$ in this setting, rivaroxaban, low-dose dabigatran (110 mg bid), and both doses of edoxaban (60 mg once daily [od] and $30 \mathrm{mg}$ od) were shown to be noninferior to warfarin (Table 4). ${ }^{32,33,36,37}$ The
AVERROES study was terminated early owing to a clear benefit of apixaban over ASA for the prevention of stroke and systemic embolism. ${ }^{35}$

Different major bleeding definitions were used in the Phase III clinical studies of the direct oral anticoagulants, and enrolled patients had different baseline bleeding risks. Nonetheless, the direct oral anticoagulants were associated with a similar or lower incidence of major bleeding compared with warfarin (Table 4) $)^{32-34,36-38}$ or ASA. ${ }^{35}$ The risk of intracranial hemorrhage ( $\mathrm{ICH}$; the most serious complication of anticoagulation therapy ${ }^{39}$ ) was 33\%-70\% lower in patients treated with a direct oral anticoagulant than in those treated with warfarin (Table 4). ${ }^{32-36,38,40}$ Fatal bleeding rates were also lower in patients treated with apixaban, rivaroxaban, edoxaban, and low-dose (110 mg bid) dabigatran compared with patients treated with warfarin; similar rates of fatal bleeding were seen in patients treated with high-dose (150 mg bid) dabigatran (Table 4). ${ }^{33,34,36,41}$ In the AVERROES study comparing apixaban with ASA, rates of $\mathrm{ICH}$ and fatal bleeding were comparable in both treatment groups. ${ }^{35}$

Table 3 Study designs for ARISTOTLE, AVERROES, RE-LY, ENGAGE AF-TIMI 48, and ROCKET AF

\begin{tabular}{|c|c|c|c|c|c|}
\hline & ARISTOTLE 34 & AVERROES 35 & RE-LY $Y^{32}$ & $\begin{array}{l}\text { ENGAGE } \\
\text { AF-TIMI } 48^{36}\end{array}$ & ROCKET AF AF $^{33}$ \\
\hline Study drug & Apixaban & Apixaban & Dabigatran & Edoxaban & Rivaroxaban \\
\hline Comparator & Warfarin & ASA & Warfarin (open-label) & Warfarin & Warfarin \\
\hline \multicolumn{6}{|l|}{ Study design } \\
\hline Blinding & $\begin{array}{l}\text { Double-blind, } \\
\text { double-dummy }\end{array}$ & $\begin{array}{l}\text { Double-blind, } \\
\text { double-dummy }\end{array}$ & $\begin{array}{l}\text { Blinded dabigatran } \\
\text { (two doses) }\end{array}$ & $\begin{array}{l}\text { Double-blind, } \\
\text { double-dummy }\end{array}$ & $\begin{array}{l}\text { Double-blind, } \\
\text { double-dummy }\end{array}$ \\
\hline Statistical objective & Noninferiority & Superiority & Noninferiority & Noninferiority & Noninferiority \\
\hline Doses studied & 5 mg bid & 5 mg bid & $\begin{array}{l}\text { I } 10 \mathrm{mg} \text { bid and } \\
150 \mathrm{mg} \text { bid }\end{array}$ & $\begin{array}{l}30 \mathrm{mg} \text { od and } \\
60 \mathrm{mg} \mathrm{od}^{\mathrm{b}}\end{array}$ & $20 \mathrm{mg} \mathrm{od}^{\mathrm{c}}$ \\
\hline Number of risk factors & $\geq 1$ & $\geq 1$ & $\geq 1$ & $\geq 1$ & $\geq 2$ \\
\hline \multicolumn{6}{|l|}{ Study outcomes } \\
\hline Primary efficacy & $\begin{array}{l}\text { Composite of } \\
\text { stroke and systemic } \\
\text { embolism }\end{array}$ & $\begin{array}{l}\text { Composite of } \\
\text { stroke and systemic } \\
\text { embolism }\end{array}$ & $\begin{array}{l}\text { Composite of } \\
\text { stroke and systemic } \\
\text { embolism }\end{array}$ & $\begin{array}{l}\text { Composite of } \\
\text { stroke and systemic } \\
\text { embolism }\end{array}$ & $\begin{array}{l}\text { Composite of } \\
\text { stroke and systemic } \\
\text { embolism }\end{array}$ \\
\hline Principal safety & Major bleeding ${ }^{d}$ & Major bleeding ${ }^{d}$ & Major bleeding & Major bleeding ${ }^{f}$ & $\begin{array}{l}\text { Major }^{g} \text { and } \\
\text { nonmajor clinically } \\
\text { relevant bleeding }\end{array}$ \\
\hline
\end{tabular}

Notes: ${ }^{\mathrm{A}} \mathrm{A}$ reduced dose of apixaban $(2.5 \mathrm{mg}$ bid) was used in patients with $\geq 2$ of the following criteria: age $\geq 80$ years, body weight $\leq 60 \mathrm{~kg}$, or a serum creatinine level $\geq 1.5$ $\mathrm{mg} / \mathrm{dL}$; both doses of edoxaban were halved if the patients had $\mathrm{CrCl}$ of $30-50 \mathrm{~mL} / \mathrm{min}$; body weight $\leq 60 \mathrm{~kg}$; or concomitant use of verapamil, quinidine, or dronedarone at randomization or during the study; ca reduced dose of rivaroxaban ( $15 \mathrm{mg}$ od) was used in patients with moderate renal impairment (CrCl $30-49 \mathrm{~mL} / \mathrm{min})$; ${ }^{\mathrm{d}}$ defined according to the criteria of the ISTH as clinically overt bleeding accompanied by a decrease in hemoglobin level of $\geq 2 \mathrm{~g} / \mathrm{dL}$ over a 24 -hour period or transfusion of $\geq 2$ units of whole blood or red cells, occurring at a critical site or resulting in death; edefined as a reduction in hemoglobin level of $\geq 20 \mathrm{~g} / \mathrm{L}$, transfusion of $\geq 2$ units of blood, or symptomatic bleeding in a critical area or organ; fdefined as clinically overt bleeding associated with fatal outcome, involving a critical site, or clinically overt bleeding associated with a fall in hemoglobin concentration of $\geq 2 \mathrm{~g} / \mathrm{dL}$ adjusted for blood transfusions or a fall in hematocrit of $\geq 6.0 \%$ adjusted for blood transfusions; ${ }^{\mathrm{g}} \mathrm{defined}$ as clinically overt bleeding associated with fatal outcome, involving a critical site, or clinically overt bleeding associated with a fall in hemoglobin concentration of $\geq 2 \mathrm{~g} / \mathrm{dL}$, or leading to transfusion of $\geq 2$ units of packed red blood cells or whole blood; hdefined as overt bleeding not meeting the criteria for major bleeding but associated with medical intervention, unscheduled contact with a physician (visit or telephone call), temporary cessation (ie, by delaying the next administration) of study drug, pain, or impairment of daily activities.

Abbreviations: ARISTOTLE, Apixaban for Reduction In STroke and Other ThromboemboLic Events in atrial fibrillation; ASA, acetylsalicylic acid; AVERROES, Apixaban VERsus acetylsalicylic acid to pRevent stroke in atrial fibrillation patients who have failed Or are unsuitabIE for vitamin $\mathrm{K}$ antagoniSt treatment; bid, twice daily; $\mathrm{CrCl}$, creatinine clearance; ENGAGE AF-TIMI 48, Effective Anticoagulation With Factor Xa Next Generation in Atrial Fibrillation-Thrombolysis In Myocardial Infarction Study 48; ISTH, International Society on Thrombosis and Haemostasis; od, once daily; RE-LY, Randomized Evaluation of Long-term anticoagulation therapy; ROCKET AF, Rivaroxaban Once daily, oral, direct factor Xa inhibition Compared with vitamin K antagonism for prevention of stroke and Embolism Trial in Atrial Fibrillation. 
Table 4 Summary of key findings from the four Phase III outcome trials of rivaroxaban, apixaban, edoxaban, and dabigatran versus warfarin in patients with atrial fibrillation

\begin{tabular}{|c|c|c|c|c|c|c|}
\hline \multirow[t]{2}{*}{ Trial name and direct OAC } & \multirow{2}{*}{$\frac{\text { ARISTOTLE }^{34}}{\text { Apixaban }}$} & \multicolumn{2}{|l|}{ RE-LY ${ }^{32,37,38,41}$} & \multicolumn{2}{|c|}{ ENGAGE AF-TIMI $48^{36}$} & \multirow{3}{*}{$\frac{\frac{\text { ROCKET AF }}{\text { Rivaroxaban }}}{20 \mathrm{mg} \mathrm{od}^{\mathrm{c}}}$} \\
\hline & & \multicolumn{2}{|l|}{ Dabigatran } & \multicolumn{2}{|l|}{ Edoxaban } & \\
\hline Direct OAC dose & 5 mg bid ${ }^{a}$ & I 10 mg bid & I50 mg bid & $30 \mathrm{mg} \mathrm{od}^{\mathrm{b}}$ & $60 \mathrm{mg} \mathrm{od}^{\mathrm{b}}$ & \\
\hline \multicolumn{7}{|l|}{ Patient characteristics } \\
\hline Total number of patients & $|8,20|$ & \multicolumn{2}{|c|}{18,113} & \multicolumn{2}{|c|}{21,105} & 14,264 \\
\hline Median age, years & 70 vs 70 & 71 vs $72^{d}$ & 72 vs $72^{d}$ & 72 vs 72 & 72 vs 72 & 73 vs 73 \\
\hline Mean $\mathrm{CHADS}_{2}$ score & 2.1 vs 2.1 & 2.1 vs 2.1 & 2.2 vs 2.1 & 2.8 vs 2.8 & 2.8 vs 2.8 & 3.5 vs 3.5 \\
\hline Prior stroke or TIA, \% & 19 vs 20 & 20 vs 20 & 20 vs 20 & 29 vs 28 & 28 vs 28 & 55 vs 55 \\
\hline Mean TTR (warfarin patients), \% & 62 & \multicolumn{2}{|c|}{64} & \multicolumn{2}{|l|}{65} & 55 \\
\hline \multicolumn{7}{|c|}{ Main outcomes (relative risk vs warfarin) } \\
\hline Stroke or systemic embolisme & $0.79(0.66-0.95)^{f}$ & $0.89(0.73-1.09)$ & $0.65(0.52-0.8 I)$ & $1.13(0.93-0.34)^{g}$ & $0.87(0.73-1.04)^{g}$ & $0.88(0.75-1.03)^{\mathrm{h}}$ \\
\hline Major bleedingi & $0.69(0.60-0.80)^{f}$ & $0.80(0.70-0.93)$ & $0.94(0.82-1.08)$ & $0.47(0.4 I-0.55)$ & $0.80(0.7|-0.9|)$ & $1.04(0.90-1.20)$ \\
\hline Intracranial bleedingi & $0.42(0.30-0.58)^{f}$ & $0.30(0.19-0.45)$ & $0.4 I(0.28-0.60)$ & $0.30(0.2 \mathrm{I}-0.43)$ & $0.47(0.34-0.63)$ & $0.67(0.47-0.93)$ \\
\hline Gastrointestinal bleeding' & $0.89(0.70-1.15)^{f}$ & $1.08(0.85-1.38)$ & $1.48(1.18-1.85)$ & $0.67(0.53-0.83)$ & $1.23(1.02-1.50)$ & $\begin{array}{l}3.15 \% \text { vs } 2.16 \% \\
P<0.00 I\end{array}$ \\
\hline Fatal bleedingi & 34 vs 55 patients ${ }^{e}$ & $0.58(0.35-0.97)$ & $0.7(0.43-1.14)$ & $0.35(0.2 \mathrm{I}-0.57)$ & $0.55(0.36-0.84)$ & $0.50(0.31-0.79)$ \\
\hline
\end{tabular}

Notes: $2.5 \mathrm{mg}$ bid in patients with $\geq 2$ of the following: age $\geq 80$ years, body weight $\leq 60 \mathrm{~kg}$, serum creatinine $\geq 1.5 \mathrm{mg} / \mathrm{dL}$; bhalving of dose if $\mathrm{CrCl} 30-50 \mathrm{~mL} / \mathrm{min}$; body weight $\leq 60 \mathrm{~kg}$; or concomitant use of verapamil, quinidine, or dronedarone; ' $15 \mathrm{mg}$ od in patients with $\mathrm{CrCl} 30-49 \mathrm{~mL} / \mathrm{min}$; ${ }^{\mathrm{d}} \mathrm{mean}$; elTT population; 'hazard ratio ( $95 \%$ $\mathrm{Cl}$ ); sthe primary efficacy analysis was prespecified to be performed in the on-treatment modified ITT population set that includes all randomized subjects who received $\geq 1$ dose of randomized study drug. The treatment period was defined as the period between administration of the first dose of the study drug and either 3 days after the receipt of the last dose or the end of the double-blind therapy; ${ }^{\text {the }}$ primary efficacy analysis was prespecified to be performed in the per-protocol population, which included all patients who received $\geq I$ dose of a study drug, did not have a major protocol violation, and were followed for events while receiving a study drug or within 2 days after discontinuation; 'safety population.

Abbreviations: ARISTOTLE, Apixaban for Reduction In STroke and Other ThromboemboLic Events in Atrial Fibrillation; bid, twice daily; CHADS, Congestive heart failure, Hypertension, Age $\geq 75$ years, Diabetes mellitus, and Stroke or TIA previous event (2 points); Cl, confidence interval; CrCl, creatinine clearance; ENGAGE AFTIMI 48, Effective Anticoagulation With Factor Xa Next Generation in Atrial Fibrillation-Thrombolysis In Myocardial Infarction Study 48; ITT, intent-to-treat; OAC, oral anticoagulant; od, once daily; RE-LY, Randomized Evaluation of Long-term anticoagulation therapy; ROCKET AF, Rivaroxaban Once daily, oral, direct factor Xa inhibition Compared with vitamin $\mathrm{K}$ antagonism for prevention of stroke and Embolism Trial in Atrial Fibrillation; TIA, transient ischemic attack; TTR, time in therapeutic range for international normalized ratio.

The incidence of major gastrointestinal (GI) bleeding varied with the use of the different direct oral anticoagulants. Compared with warfarin, a lower incidence of major GI bleeding was observed in the low-dose ( $30 \mathrm{mg}$ od) edoxaban group; a similar incidence was observed in the apixaban and lowdose dabigatran (110 mg bid) groups; and a higher incidence was observed in patients treated with high-dose $(150 \mathrm{mg}$ bid $)$ dabigatran, rivaroxaban, or high-dose edoxaban $(60 \mathrm{mg}$ od) (Table 4). ${ }^{32-34,36,38}$ Similar rates of major GI bleeding were observed between patients treated with apixaban and ASA. ${ }^{35}$

Non-bleeding-related adverse events occurred at a similar rate in direct oral anticoagulant-treated and warfarin-treated patients in the ROCKET AF, ARISTOTLE, and ENGAGE studies. ${ }^{33,34,36}$ In the RE-LY study, a significantly greater incidence of dyspepsia was observed in dabigatran-treated patients compared with warfarin-treated patients; rates of other non-bleeding-related adverse events were similar in the two treatment groups. ${ }^{32}$

\section{Current guideline recommendations for stroke prevention}

The ESC 2012 guidelines state a preference for the use of the direct oral anticoagulants approved for stroke prevention in patients with nonvalvular AF, given that they offer better efficacy, safety, and convenience profiles compared with VKAs. ${ }^{8}$ The guidelines do not recommend a single direct anticoagulant over another, because direct comparisons are not available. Further guidance about necessary dose adjustments based on age, the use of concomitant interacting drugs, bleeding risk, and renal function is also given. ${ }^{8}$ A summary of the recommendations for the use of the direct oral anticoagulants for the prevention of stroke in patients with AF is shown in Table 5 as per their respective European approved Summaries of Product Characteristics (SmPCs). ${ }^{23-25}$

\section{Optimizing patient management}

Although the most recent guidelines for stroke prevention in patients with $\mathrm{AF}$ are intended to guide the optimal care of patients, particularly when the selection of treatment is based on patient demographics (eg, stroke or bleeding risk), an understanding of the pharmacological characteristics of the drug and the implications for management are also important. Some of the main management issues, together with the recommendations provided by the European SmPC for each direct oral anticoagulant, are discussed below. ${ }^{23-25}$ 


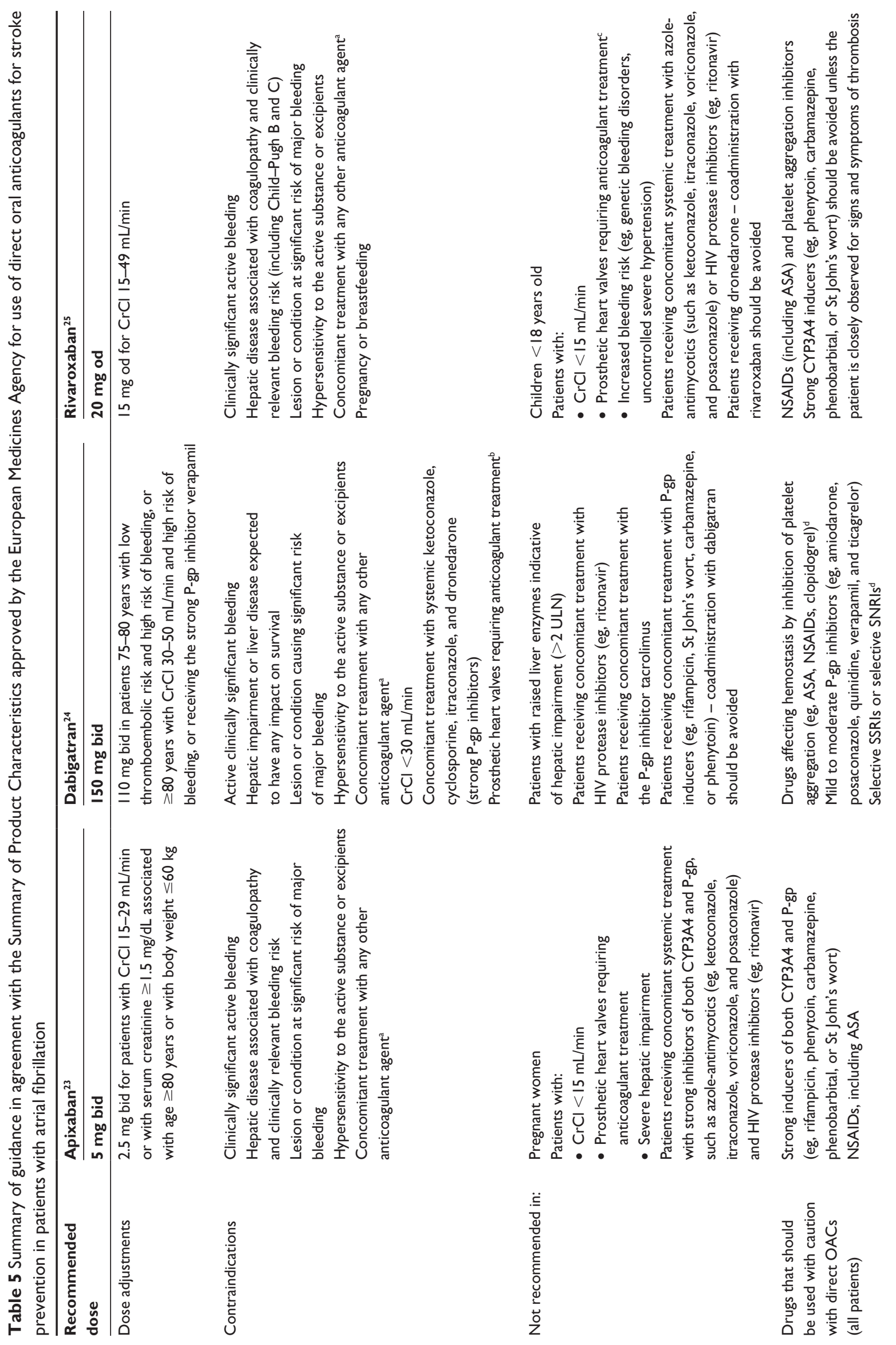



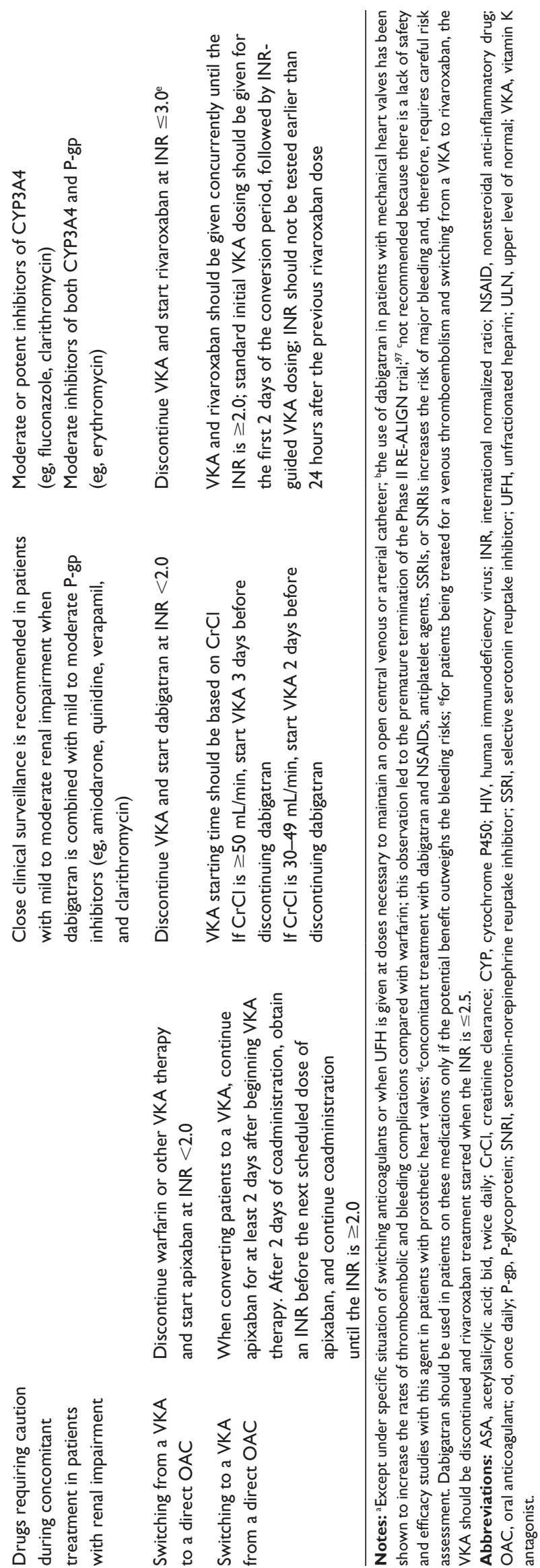

\section{Patients with renal impairment}

Renal impairment is an important consideration in patients with $\mathrm{AF}$ who are receiving apixaban, dabigatran, or rivaroxaban and will also be the case for those receiving edoxaban when this agent gains approval, because all four agents are eliminated renally (to a greater or lesser extent) (Table 2). Renal excretion accounts for approximately $27 \%$ of total clearance of apixaban..$^{23}$ For rivaroxaban, one-third of the administered dose undergoes direct renal excretion as unchanged active substance in the urine. ${ }^{25}$ Approximately $35 \%-39 \%$ of edoxaban is eliminated via renal excretion. ${ }^{42}$ Dabigatran is eliminated primarily in the urine, and renal clearance of dabigatran accounts for $85 \%$ of total clearance after intravenous administration. ${ }^{24}$ Varying degrees of renal impairment will, therefore, lead to increased drug exposure, which may increase the risk of bleeding. ${ }^{30}$

In the Phase III trials of direct oral anticoagulants, patients with nonvalvular $\mathrm{AF}$ and severe renal impairment (creatinine clearance [CrCl] $<25 \mathrm{~mL} / \mathrm{min}$ [ARISTOTLE] or $<30 \mathrm{~mL} /$ min [ENGAGE AF-TIMI 48, RE-LY, and ROCKET AF]) were excluded. ${ }^{32-34,36,43}$ Dose adjustments were made for patients who had moderate renal impairment in the studies of the three Factor Xa inhibitors. In ARISTOTLE, apixaban $2.5 \mathrm{mg}$ bid, rather than $5 \mathrm{mg}$ bid, was allocated to patients expected to have a higher drug exposure, namely, any patients with two of the following criteria: age $\geq 80$ years, body weight $\leq 60 \mathrm{~kg}$, or serum creatinine level $\geq 1.5 \mathrm{mg} / \mathrm{dL}$ $(133 \mu \mathrm{mol} / \mathrm{L}){ }^{34}$ Patients in the ENGAGE AF-TIMI 48 trial were randomized to either the edoxaban 30 or $60 \mathrm{mg}$ dose groups. A halving of both doses occurred in patients who had any one of the following, whether at randomization or at any time during the study: $\mathrm{CrCl} 30-50 \mathrm{~mL} / \mathrm{min}$; body weight $\leq 60$ $\mathrm{kg}$; or receiving verapamil, quinidine, or dronedarone. ${ }^{36} \mathrm{In}$ ROCKET AF, patients with $\mathrm{CrCl} 30-49 \mathrm{~mL} / \mathrm{min}$ received rivaroxaban $15 \mathrm{mg}$ od, instead of the $20 \mathrm{mg}$ od dose given to patients with noncompromised renal function..$^{33}$ Despite $19 \%$ of patients in RE-LY having a $\mathrm{CrCl}<50 \mathrm{~mL} / \mathrm{min}$, no dose adjustment was made. ${ }^{32}$

The corresponding percentages of patients with reduced renal function were approximately $15 \%(\mathrm{CrCl}>30-50 \mathrm{~mL} /$ $\mathrm{min}$ ) in ARISTOTLE; $19 \%$ and 20\% for low- and high-dose edoxaban $(\mathrm{CrCl} \leq 50 \mathrm{~mL} / \mathrm{min})$, respectively, in ENGAGE AF-TIMI 48; and 21\% (CrCl, 30-49 $\mathrm{mL} / \mathrm{min})$ in ROCKET $\mathrm{AF}^{33,34,36}$ In the apixaban and rivaroxaban studies, and irrespective of treatment assignment, patients with renal impairment had numerically higher rates of stroke or major bleeding events than patients without renal impairment. ${ }^{32,34,36,43} \mathrm{In}$ ARISTOTLE, for patients without renal impairment 
( $\mathrm{CrCl}>80 \mathrm{~mL} / \mathrm{min})$ treated with apixaban, major bleeding was $1.5 \%$ per year; this rate increased to $2.5 \%$ and $3.2 \%$ per year for those with mild $(\mathrm{CrCl}>50-80 \mathrm{~mL} / \mathrm{min})$ and moderate $(\mathrm{CrCl}>30-50 \mathrm{~mL} / \mathrm{min})$ or severe $(\mathrm{CrCl} \leq 30 \mathrm{~mL} / \mathrm{min})$ renal impairment, respectively. ${ }^{34}$ Apixaban was associated with significantly fewer major bleeding events in patients with moderate or severe renal impairment compared with warfarin ( $P=0.03$ for interaction). ${ }^{34}$

No data are yet available regarding the rates of stroke and major bleeding in patients with renal impairment receiving edoxaban, although the reduction in major bleeding with edoxaban compared with warfarin was greater among dosereduced patients than among those who did not receive a dose reduction. ${ }^{36}$ However, the recent US Food and Drug Administration (FDA) approval of edoxaban limits its use to patients with a $\mathrm{CrCl} \leq 95 \mathrm{~mL} / \mathrm{min}$ on the basis that patients with a $\mathrm{CrCl}>95 \mathrm{~mL} / \mathrm{min}$ had an increased rate of ischemic stroke with high-dose edoxaban (60 mg od) compared with patients treated with warfarin. ${ }^{26}$

In RE-LY, the major bleeding rates for dabigatran 110 and $150 \mathrm{mg}$ were $1.53 \%$ and $2.09 \%$ per year, respectively, in patients with no renal impairment $(\mathrm{CrCl}>80 \mathrm{~mL} / \mathrm{min})$; $2.89 \%$ and $3.33 \%$ per year, respectively, for patients with mild renal impairment $(\mathrm{CrCl} 50-79 \mathrm{~mL} / \mathrm{min})$; and 5.29\% and $5.44 \%$ per year, respectively, in patients with moderate $(\mathrm{CrCl}<50 \mathrm{~mL} / \mathrm{min})$ renal impairment. ${ }^{41}$ Major bleeding in ROCKET AF was similar for the rivaroxaban and warfarin groups (3.6\% versus $3.4 \%$ per year; $P=0.58)$; $^{33}$ in a subgroup analysis of patients with renal impairment, the rates of major bleeding for rivaroxaban and warfarin were 3.39\% versus $3.17 \%$ per year $(\mathrm{CrCl} \geq 50 \mathrm{~mL} / \mathrm{min})$ and $4.49 \%$ versus $4.70 \%$ per year ( $\mathrm{CrCl} 30-49 \mathrm{~mL} / \mathrm{min})$, respectively. ${ }^{43}$ The efficacy and safety profiles of apixaban, dabigatran, and rivaroxaban versus warfarin were consistent across subgroups representing decreasing renal function..$^{32,35,41,43}$ These results are supported by a recently published meta-analysis based on the results of the Phase III clinical trials of the direct oral anticoagulants for stroke prevention and VTE treatment, which has shown that, in patients with renal insufficiency, recommended doses of direct oral anticoagulants are noninferior and relatively safe compared with conventional anticoagulants. ${ }^{44}$

Because of the potential for raised plasma drug levels in patients with severe renal impairment $(\mathrm{CrCl}<30 \mathrm{~mL} / \mathrm{min})$, the use of dabigatran is contraindicated in these patients. ${ }^{24}$ Rivaroxaban should be used with caution in patients with $\mathrm{CrCl}$ of $15-29 \mathrm{~mL} / \mathrm{min}$, and rivaroxaban and apixaban are not recommended in patients with $\mathrm{CrCl}<15 \mathrm{~mL} / \mathrm{min} .^{23,25}$ Although no dose adjustment is required in patients with mild renal impairment ( $\mathrm{CrCl} 50-80 \mathrm{~mL} / \mathrm{min})$, reduced dosing is necessary with increasing degrees of renal impairment and in patients with renal impairment at increased risk of bleeding (Table 5). Concomitant treatment with drugs that target the pathways of elimination may further increase bleeding risk. A full listing of the drugs requiring caution during concomitant treatment in patients with renal impairment is given in Table 5. ${ }^{23-25}$ These drugs should be used in patients with renal impairment only if the potential benefits outweigh the risks.

The ESC 2012 guidelines recommend assessing renal function using $\mathrm{CrCl}$ for patients on all direct oral anticoagulants, but especially for patients taking dabigatran, which has a high renal clearance. ${ }^{8}$ Annual assessment of renal function is recommended, and patients with moderate renal impairment $(\mathrm{CrCl} 30-49 \mathrm{~mL} / \mathrm{min})$ should be assessed more regularly (2-3 times per year). ${ }^{8}$ Renal function may be assessed more frequently if necessary, particularly for patients $>75$ years of age and in clinical situations in which renal function could decline or deteriorate, such as hypovolemia, urosepsis, or with initiation of potentially nephrotoxic agents. ${ }^{8,24}$

\section{Patients with recent stroke}

Subgroup analyses from Phase III trials showed that the favorable efficacy and safety evident in the main population was not significantly different for patients with previous stroke or TIA. ${ }^{45-47}$ Nevertheless, the benefit of direct oral anticoagulants in patients with a recent stroke has not been established because the Phase III studies excluded patients who had had an acute stroke within 1-2 weeks of randomization or severe disabling stroke within 3-6 months of randomization. ${ }^{33,48-50}$ Decisions about restarting anticoagulation in these patients remain challenging. A large systematic review involving 23,748 patients with acute ischemic stroke showed that restarting anticoagulation within the first few days of the stroke did reduce the incidence of recurrent stroke but increased symptomatic ICH. ${ }^{51}$ Other studies have shown that there is no net benefit in terms of reducing recurrent stroke in the short term (12 days) or of morbidity/mortality in the long term (1 year). ${ }^{52}$

The practical guide from the European Heart Rhythm Association (EHRA) suggests that continuation with direct oral anticoagulants after ischemic stroke should be guided by the size of the infarct. As a rule of thumb, it is suggested that anticoagulants are recommenced 1 day after a TIA; 3 days after a small, nondisabling infarct; and 6 days after a moderate stroke. ${ }^{53}$ After a large stroke, because the risks 
of hemorrhagic transformation of the infarct are greater, anticoagulant therapy should be delayed for at least 2 weeks after the presenting event. ${ }^{53,54}$ Evidence from communitybased studies indicates that the risk of recurrence after stroke varies from $1.7 \%$ to $4.0 \%$ in the first 30 days. ${ }^{55}$

\section{Patients undergoing cardioversion}

Cardioversion increases the risk of thromboembolism, and anticoagulation is recommended before and after electrical or pharmacological cardioversion of AF. ${ }^{15,56}$ To date, rivaroxaban is the only direct oral anticoagulant that has completed a Phase III clinical study in this indication. The $\mathrm{X}$-VeRT study (eXplore the efficacy and safety of once-daily oral riVaroxaban for the prevention of caRdiovascular events in patients with nonvalvular aTrial fibrillation scheduled for cardioversion) was an exploratory study in which patients were randomly assigned to rivaroxaban or VKA before undergoing early or delayed electrical or pharmacological cardioversion. ${ }^{57}$ The primary efficacy outcome (a composite of stroke, TIA, peripheral embolism, MI, and cardiovascular death) occurred numerically less often in patients assigned to rivaroxaban than VKA $(0.51 \%$ versus $1.02 \%$; risk ratio: 0.5 ; $95 \%$ confidence interval: $0.15-1.73)$, and major bleeding rates were similar in both treatment arms $(0.61 \%$ versus $0.80 \%$; risk ratio: $0.76 ; 95 \%$ confidence interval: $0.21-2.67$ ). Furthermore, the time between randomization and cardioversion was similar or shorter in patients assigned to rivaroxaban compared with VKA (early: median $=1$ [interquartile range: $1-2]$ versus 1 [1-3] days, $P=0.628$; delayed: 22 [21-26] versus 30 [23-42] days; $P<0.001$ ). Overall, the results of the $\mathrm{X}$-VeRT study suggest that rivaroxaban is an effective and safe alternative to VKAs in patients with AF undergoing cardioversion and may allow for more prompt cardioversion. ${ }^{57}$ Although planned cardioversion was an exclusion criterion in ROCKET AF, a small number of patients (285 patients) underwent cardioversion. The results of a subgroup analysis in this group of patients support those from the X-VeRT study; rates of stroke or systemic embolism, or death from any cause, were reported to be similar for patients treated with rivaroxaban or warfarin after cardioversion. ${ }^{58}$

In RE-LY, patients undergoing cardioversion were recommended to remain on dabigatran. Of 18,113 patients randomized, $7 \%$ had cardioversions. In these patients, the rate of stroke or systemic embolism was low, and major bleeding was infrequent in all patient groups. ${ }^{32,59}$ Rates of stroke or systemic embolism were $0.77 \%, 0.30 \%$, and $0.60 \%$, and rates of major bleeding were $1.7 \%, 0.6 \%$, and $0.6 \%$ in the dabigatran $110 \mathrm{mg}$, dabigatran $150 \mathrm{mg}$, and warfarin groups, respectively. ${ }^{59}$ Rates of thromboembolism were similar for patients receiving conventional and transesophageal echocardiogram-guided cardioversions. These findings confirmed that dabigatran is a valid alternative to warfarin in patients requiring cardioversion. ${ }^{59}$ In ARISTOTLE, a post hoc analysis of patients undergoing cardioversion reported that major cardiovascular events (including stroke or systemic embolism, MI, or death) after cardioversion are rare and comparable between patients treated with apixaban or warfarin. ${ }^{60}$ The effectiveness of apixaban compared with VKAs in patients with nonvalvular AF undergoing early cardioversion is currently being investigated in the ongoing Phase IV clinical study, EMANATE. ${ }^{61}$

At the time the ESC guidelines on the management of patients with AF undergoing cardioversion were written, the only published study of a direct oral anticoagulant in this setting was the preliminary RE-LY post hoc analysis; therefore, only dabigatran (or VKA) was included in the recommendations. ${ }^{8}$ The more recent EHRA practical guide, published in 2013 after the publication of preliminary results of post hoc analyses of patients undergoing cardioversion in the ROCKET AF and ARISTOTLE trials, suggests that cardioversion is acceptably safe in patients treated with any of the three approved direct oral anticoagulants, providing compliance can be reliably confirmed. If there are any doubts about compliance, transesophageal echocardiogram should be performed prior to the procedure to exclude the presence of left atrial thrombi. ${ }^{53}$

\section{Patients with atrial fibrillation requiring concomitant antiplatelet therapy}

The management of patients with AF who experience an ACS event and require percutaneous coronary intervention (PCI) with stenting is challenging because combined anticoagulant and antiplatelet treatment is warranted. At present, no data are available from the clinical trials of the direct oral anticoagulants in patients with AF undergoing PCI. ESC guidelines recommend VKA therapy (with a target international normalized ratio [INR] of 2.0-2.5) in combination with DAPT after PCI and stent placement. ${ }^{15,62,63}$ However, since these guidelines have been published, management practices for patients with AF have significantly evolved with the approval of the direct oral anticoagulants, and newergeneration drug-eluting stents (which may be less thrombogenic) have been developed. In light of these changes, the ESC and EHRA, together with the European Association of Percutaneous Cardiovascular Interventions and European Association of Acute Cardiac Care, have recently published 
a consensus document regarding the management of patients with AF and ACS (or stable coronary artery disease) who require PCI with stenting. ${ }^{64}$ Specific recommendations for the duration of combined anticoagulant and single or dual antiplatelet therapy are given, dependent on a patient's stroke risk, their bleeding risk, and the clinical setting (elective PCI or urgent PCI owing to ACS) ${ }^{64}$ Further details can be found in Table 6. Given that combination therapy of antiplatelet agents with a VKA or direct oral anticoagulant (at intensities used for stroke prevention) is associated with elevated risks of bleeding, ${ }^{65-69}$ a lower-intensity anticoagulant regimen is recommended (target INR of 2.0-2.5 for VKAs; direct oral anticoagulants at the lower tested dose in AF trials [ie, apixaban $2.5 \mathrm{mg}$ bid, rivaroxaban $15 \mathrm{mg}$ od, dabigatran $110 \mathrm{mg}$ bid]). ${ }^{64}$ Additional recommendations include the use of proton pump inhibitors (to minimize the risk of GI bleeding, particularly when ASA is used), and the use of newer-generation drug-eluting stents over bare metal stents, especially in patients at a low risk of bleeding. ${ }^{64}$

In patients with AF undergoing PCI with stent placement, there is currently no information available to compare the elevated bleeding risk of combined therapy with an antiplatelet and a VKA versus combined therapy with an antiplatelet and a direct oral anticoagulant. Phase III clinical trials are ongoing in this setting. PIONEER-AF-PCI ${ }^{70}$ is evaluating the safety of two different rivaroxaban regimens $(2.5 \mathrm{mg}$ bid or $15 \mathrm{mg}$ od [10 $\mathrm{mg}$ od in patients with renal impairment]) compared with a VKA regimen; all patients will receive concomitant treatment with various combinations of DAPT or low-dose ASA or clopidogrel (or prasugrel or ticagrelor). In RE-DUAL PCI, ${ }^{71}$ two doses of dabigatran $(110 \mathrm{mg}$ bid or $150 \mathrm{mg}$ bid) plus single antiplatelet therapy are being

Table 6 Consensus recommendations for antithrombotic management of patients with atrial fibrillation after percutaneous coronary intervention

\begin{tabular}{|c|c|c|c|c|c|}
\hline \multirow{2}{*}{$\begin{array}{l}\text { Hemorrhage } \\
\text { risk }\end{array}$} & \multirow{2}{*}{$\begin{array}{l}\text { Clinical } \\
\text { setting }\end{array}$} & \multirow{2}{*}{$\begin{array}{l}\text { Stroke } \\
\text { risk }^{\mathrm{a}}\end{array}$} & \multicolumn{3}{|c|}{ Recommendations for antithrombotic therapy } \\
\hline & & & $\begin{array}{l}\text { Timing of treatment } \\
\text { after } \mathrm{PCI}\end{array}$ & Therapy & Details \\
\hline \multirow{12}{*}{$\begin{array}{l}\text { Low or moderate } \\
\text { (HAS-BLED } \leq 2 \text { ) }\end{array}$} & Stable CAD & Moderate & $\geq 4$ weeks $<6$ months & Triple therapy ${ }^{b}$ & Reduced-dose OAC + ASA + clopidogrel \\
\hline & (elective $\mathrm{PCl}$ ) & & Up to I2th month & Dual therapyc & Reduced-dose OAC + clopidogrel or \\
\hline & & & & & Reduced-dose OAC + ASA \\
\hline & & & Lifelong & Single therapy & Standard-dose $O A C^{d}$ \\
\hline & & High & $\geq 4$ weeks $<6$ months & Triple therapy ${ }^{e}$ & Reduced-dose OAC + ASA + clopidogrel \\
\hline & & & Up to I2th month & Dual therapy & Reduced-dose OAC + clopidogrel or \\
\hline & & & & & Reduced-dose OAC + ASA \\
\hline & & & Lifelong & Single therapy & Standard-dose OAC \\
\hline & ACS & Moderate & Up to 6 th month & Triple therapy & Reduced-dose OAC + ASA + clopidogrel \\
\hline & (urgent $\mathrm{PCl}$ ) & or high & Up to 12 th month & Dual therapy ${ }^{f}$ & Reduced-dose OAC + clopidogrel or \\
\hline & & & & & Reduced-dose OAC + ASA \\
\hline & & & Lifelong & Single therapy & Standard-dose $O A C^{d}$ \\
\hline \multirow[t]{10}{*}{ High (HAS-BLED $\geq 3$ ) } & Stable CAD & Moderate & Up to 12 th month & Dual therapyc & Reduced-dose OAC + clopidogrel \\
\hline & (elective $\mathrm{PCl}$ ) & & Lifelong & Single therapy & Standard-dose $O A C^{d}$ \\
\hline & & High & 4 weeks & Triple therapy ${ }^{b}$ & Reduced-dose OAC + ASA + clopidogrel \\
\hline & & & Up to 12 th month & Dual therapy & Reduced-dose OAC + clopidogrel or \\
\hline & & & & & Reduced-dose OAC + ASA \\
\hline & & & Lifelong & Single therapy & Standard-dose OAC \\
\hline & ACS & Moderate & 4 weeks & Triple therapy ${ }^{\mathrm{e}}$ & Reduced-dose OAC + ASA + clopidogrel \\
\hline & (urgent $\mathrm{PCl}$ ) & or high & Up to 12th month & Dual therapy & Reduced-dose OAC + clopidogrel or \\
\hline & & & & & Reduced-dose OAC + ASA \\
\hline & & & Lifelong & Single therapy & Standard-dose OAC \\
\hline
\end{tabular}

Notes: Unless specified, ASA dose is 75-100 mg/day and clopidogrel dose is $75 \mathrm{mg} /$ day. Reduced-dose OAC refers to either a VKA with a target INR of $2.0-2.5$ or direct OAC at the lowest tested dose in AF (apixaban $2.5 \mathrm{mg}$ bid, rivaroxaban $15 \mathrm{mg}$ od, or dabigatran $110 \mathrm{mg}$ bid). Tailored guidance for patients with AF already on a reduced dose of direct $\mathrm{OAC}$ before a $\mathrm{PCl}$ is not given. ${ }^{\text {a }}$ Stroke risk assessed via $\mathrm{CHA}_{2} \mathrm{DS}_{2}-\mathrm{VASc}$; moderate risk is defined as a score of $\mathrm{I}$, high risk is defined as a score of $\geq 2$; only male patients with $\mathrm{AF}$ undergoing $\mathrm{PCl}$ can be defined as moderate risk - female patients with $\mathrm{AF}$ undergoing $\mathrm{PCl}$ will have a $\mathrm{CHA}_{2} \mathrm{DS}_{2}-\mathrm{VASc} \mathrm{score}$ of $\geq 2$; ${ }^{\mathrm{b}}$ combination of reduced-dose $\mathrm{OAC}+$ clopidogrel $75 \mathrm{mg} /$ day or dual antiplatelet therapy consisting of ASA $75 \mathrm{mg} /$ day and clopidogrel $75 \mathrm{mg} /$ day may be considered as an alternative; 'dual antiplatelet therapy consisting of ASA $75 \mathrm{mg} /$ day and clopidogrel $75 \mathrm{mg} /$ day may be considered as an alternative; in selected patients (eg, those with stenting of the left main proximal bifurcation, or recurrent myocardial infarctions), dual therapy with OAC and single antiplatelet therapy may be continued beyond 12 months; ${ }^{\mathrm{c}} \mathrm{Combination}$ of $\mathrm{OAC}$ and clopidogrel 75 mg/day may be considered as an alternative; fin selected patients at high stroke risk, continuation of triple therapy between 6 and 12 months may be considered. Data from Lip et al. ${ }^{64}$

Abbreviations: ACS, acute coronary syndrome; AF, atrial fibrillation; ASA, acetylsalicylic acid; bid, twice daily; $C A D$, coronary artery disease; $C_{2} A_{2} D S_{2}-V_{A S c}$ Congestive heart failure/left ventricular dysfunction, Hypertension, Age $\geq 75$ years (2 points), Diabetes, Stroke or transient ischemic attack previous event/thromboembolism (2 points), Vascular disease, Age 65-74 years, and Sex category (female); INR, international normalized ratio; OAC, oral anticoagulant; od, once daily; PCI, percutaneous coronary intervention; VKA, vitamin K antagonist; HAS-BLED, Hypertension, Abnormal Liver Function, Stroke History, Bleeding Predisposition, Labile INRs, Elderly, Drugs Concomitantly. 
compared with warfarin plus DAPT. Results of these studies are not expected until after 2016 and 2017, respectively.

\section{Management of bleeding}

All anticoagulants are associated with a risk of bleeding. Appropriate patient selection before initiating treatment with direct oral anticoagulants is therefore important to minimize the risk of bleeding events. Before the use of direct oral anticoagulants, standard bleeding risk stratification (eg, by HAS-BLED [Hypertension, Abnormal Liver, Stroke History, Bleeding Predisposition, Labile INRs, Elderly, Drugs] score $[\geq 3]$ ) enables identification of patients at high risk of bleeding (who must exert caution and need regular review) and may allow for correction of reversible risk factors associated with bleeding. ${ }^{15}$ Several groups of patients are recognized to be at high risk of bleeding, including patients with congenital or acquired coagulation disorders, patients with ulcerative GI disease, or patients undergoing treatment with drugs that are also associated with an increased bleeding risk, such as antiplatelet agents. ${ }^{24,25}$ For these high-risk patients, close clinical surveillance for overt bleeding (eg, regular measurement of hemoglobin and blood pressure) should be employed, and any decreases in hemoglobin or blood pressure should be investigated systematically. ${ }^{24,25}$ This investigation should include assessment for occult bleeding (eg, in stools or urine).

Standard management of patients who develop major bleeding is to delay or discontinue the anticoagulant until the source of bleeding is established. Supportive treatment includes mechanical compression, surgical hemostasis, and blood volume or full blood replacements. ${ }^{72}$ Additionally, coagulation tests may help to determine whether the bleeding is caused by an overdose or the timing of the most recent dose. ${ }^{73}$

Although the Phase III stroke prevention studies of the direct oral anticoagulants versus warfarin demonstrated an improved benefit-risk profile of direct oral anticoagulants in terms of reduced incidence of fatal bleeding and $\mathrm{ICH},{ }^{32-36,38,40}$ concern remains among physicians because there are currently no specific reversal agents for the direct oral anticoagulants in emergency situations. ${ }^{72,73}$ However, it should be remembered that, first, the reversal of the anticoagulant effects of warfarin using vitamin $\mathrm{K}$ is slow and of no use for the treatment of life-threatening bleeding; ${ }^{72}$ therefore, nonspecific reversal agents, such as prothrombin complex concentrates, are administered together with vitamin $\mathrm{K}$. Second, the antidote for low-molecular-weight heparins, protamine sulfate, can only partially counteract their anticoagulant effects. ${ }^{74}$ Lastly, the short half-life of the direct oral anticoagulants means that time is often an effective "antidote." Nonetheless, specific reversal agents for the Factor Xa inhibitors (andexanet alfa) and dabigatran (idarucizumab) are currently under development and in Phase III clinical trials $^{75-77}$ to address the unmet need for reversal agents for the direct oral anticoagulants, and they are anticipated to become available in the near future.

In the event that a patient on a direct oral anticoagulant presents with life-threatening bleeding, off-label use of nonspecific reversal agents (including prothrombin complex concentrates, recombinant Factor VIIa, and Factor VIII inhibitor bypass activity) may be considered when all other measures have failed. ${ }^{53}$ Preclinical studies (in vitro ${ }^{78-80}$ and in animal models ${ }^{81-86}$ ) and a small number of Phase I/II clinical studies in healthy volunteers ${ }^{87,88}$ have demonstrated the ability of these hemostatic agents to reverse some of the effects of the direct oral anticoagulants. However, clinical data regarding the use of prothrombin complex concentrates, recombinant Factor VIIa, and Factor VIII inhibitor bypass activity in patients presenting with bleeding events while receiving direct oral anticoagulants are limited because experience to date (in both clinical trials and real-world daily practice) suggests that most major bleeding events can be managed without the use of reversal agents. ${ }^{89,90}$

\section{Switching anticoagulation}

Management of the direct oral anticoagulants for transitioning to and from warfarin, as required by the patient's clinical situation or in the event of elective surgery (eg, orthopedic surgery or cosmetic surgery), involves an appreciation of the pharmacokinetics of the drugs. ${ }^{91}$ However, published data on which to base the management guidance for transitioning with these agents are limited..$^{91}$ In view of this lack of strong evidence, guidance specific to the anticoagulant is provided in the European SmPC (Table 5). ${ }^{23-25}$

In patients taking a direct oral anticoagulant who require transitioning to a parenteral anticoagulant, the direct oral anticoagulant should be discontinued and the first dose of the parenteral anticoagulant should be taken at the time the next dose of direct oral anticoagulant would have been due. ${ }^{23-25}$ Conversely, when switching from a parenteral agent to apixaban, the parenteral agent should be discontinued and apixaban administered at the time of the next scheduled dose. ${ }^{23}$ When switching from a parenteral agent to rivaroxaban or dabigatran, specific guidance depends on the type of parenteral agent: for a continuously infused parenteral agent (eg, unfractionated heparin), rivaroxaban or dabigatran should be administered at the time of discontinuation; 
for a parenteral agent with scheduled administration (eg, low-molecular-weight heparin), rivaroxaban or dabigatran should be given 0-2 hours before the next scheduled dose (Table 5). ${ }^{24,25}$

If transitioning from rivaroxaban or apixaban to warfarin is required in certain clinical circumstances, the Factor Xa inhibitor and warfarin should be given concurrently until the INR is $\geq 2.0$. After 2 days of coadministration, VKA dosing should be guided by INR measurement; INR should be tested just before the next scheduled dose of rivaroxaban or apixaban to minimize its influence on the measured INR. Once the INR is $\geq 2.0$, the Factor $\mathrm{Xa}$ inhibitor should be discontinued. ${ }^{23,25}$ For patients switching from dabigatran to a VKA, recommendations are based on the patient's renal function; for patients with $\mathrm{CrCl} \geq 50 \mathrm{~mL} / \mathrm{min}$, the VKA should be started 3 days before discontinuing dabigatran; for patients with moderate renal impairment $(\mathrm{CrCl} 30-50$ $\mathrm{mL} / \mathrm{min}$ ), the VKA should be started 2 days before the last intake of dabigatran. INR readings should be interpreted with caution until after dabigatran has been stopped for at least 2 days. $^{71}$

Guidance for switching from a VKA to a direct oral anticoagulant is to discontinue the VKA and, depending on the direct oral anticoagulant, initiate treatment when the INR is $<2.0$ (apixaban and dabigatran) or $\leq 3.0$ (rivaroxaban) (Table 5). ${ }^{23-25}$ Physicians should be aware that, in the case of rivaroxaban, recommendations of the target INR level when switching from VKA to rivaroxaban are indicationspecific: for patients who are being treated for a VTE and are switching from a VKA to rivaroxaban, the VKA should be stopped and rivaroxaban treatment initiated when the INR is $\leq 2.5 .^{25}$

\section{Perioperative management}

Increasingly, patients with AF taking direct oral anticoagulants may require invasive or surgical intervention. Perioperative management of anticoagulation remains a challenge to physicians, because much consideration must be given to the thromboembolic risk if anticoagulation is interrupted but also to the risk of bleeding in the presence of anticoagulation during or after any invasive procedure. After warfarin therapy is stopped, it takes approximately 4 days for the INR to reach 1.5 (the level at which surgery can safely be performed) in almost all patients. ${ }^{92}$ Heparin can be given before the operation to limit the time that the patient remains unprotected..$^{93}$ Anticoagulation using warfarin overlapping with a parenteral agent may be resumed 12 hours postoperatively (as long as the patient is not at high risk of postoperative bleeding).$^{93}$
Dosing and timing may vary according to whether the patient is at high, medium, or low risk of thrombosis. For patients on direct oral anticoagulants, anticoagulant medication should be discontinued before the procedure and restarted as soon as hemostasis is restored. ${ }^{23-25}$

The EHRA has recently published guidance on the perioperative management of patients on direct oral anticoagulants. For interventions with no clinically important bleeding risk, or where local hemostasis is possible (eg, dental extractions), the procedure may be performed at trough concentrations (ie, 12 hours after last intake of apixaban or dabigatran; 24 hours after last intake of rivaroxaban). For procedures associated with a risk of bleeding, the exact timing of treatment interruption depends on the bleeding risk of the procedure, the renal function of the patient, and the direct oral anticoagulant in use (Table 7)..$^{53}$

If a patient requires emergency surgery, anticoagulant medication should be stopped immediately. In an ideal situation, surgery should be deferred until trough plasma levels are reached, although this may be unrealistic, depending on the urgency of the situation. If surgery cannot be delayed, clinicians should evaluate the increased risk of bleeding against the urgency of the intervention. Clinical judgment regarding when the direct oral anticoagulant can be restarted is also important. ${ }^{23-25}$

Table 7 European Heart Rhythm Association recommendations for timing of treatment interruption of approved direct oral anticoagulants prior to elective surgery according to renal function and surgery bleeding risk

\begin{tabular}{|c|c|c|c|c|}
\hline \multirow{2}{*}{$\begin{array}{l}\text { Direct oral } \\
\text { anticoagulant } \\
\text { Surgery bleeding risk }\end{array}$} & \multicolumn{2}{|c|}{ Dabigatran } & \multicolumn{2}{|c|}{$\begin{array}{l}\text { Apixaban or } \\
\text { rivaroxaban }\end{array}$} \\
\hline & Low $^{a}$ & High $^{b}$ & Low $^{a}$ & High $^{b}$ \\
\hline $\begin{array}{l}\text { Normal renal function } \\
(\mathrm{CrCl} \geq 80 \mathrm{~mL} / \mathrm{min}) \text {, hours }\end{array}$ & $\geq 24$ & $\geq 48$ & $\geq 24$ & $\geq 48$ \\
\hline $\begin{array}{l}\text { Mild renal impairment } \\
(\mathrm{CrCl} 50-80 \mathrm{~mL} / \mathrm{min}) \text {, hours }\end{array}$ & $\geq 36$ & $\geq 72$ & $\geq 24$ & $\geq 48$ \\
\hline $\begin{array}{l}\text { Moderate renal impairment } \\
(\mathrm{CrCl} 30-50 \mathrm{~mL} / \mathrm{min}) \text {, hours }\end{array}$ & $\geq 48$ & $\geq 96$ & $\geq 24$ & $\geq 48$ \\
\hline $\begin{array}{l}\text { Severe renal impairment } \\
(\mathrm{CrCl} 15-30 \mathrm{~mL} / \mathrm{min}) \text {, hours }\end{array}$ & \multicolumn{2}{|c|}{$\begin{array}{l}\text { Dabigatran } \\
\text { contraindicated }\end{array}$} & $\geq 36$ & $\geq 48$ \\
\hline $\begin{array}{l}\text { Renal failure } \\
(\mathrm{CrCl}<15 \mathrm{~mL} / \mathrm{min})\end{array}$ & \multicolumn{2}{|c|}{$\begin{array}{l}\text { Dabigatran } \\
\text { contraindicated }\end{array}$} & \multicolumn{2}{|c|}{$\begin{array}{l}\text { Apixaban and } \\
\text { rivaroxaban not } \\
\text { recommended }\end{array}$} \\
\hline
\end{tabular}

Notes: a Surgeries/procedures with low risk of bleeding include: endoscopy with biopsy, prostate or bladder biopsy, electrophysiological study or radiofrequency catheter ablation for supraventricular tachycardia, angiography, and pacemaker or implantable cardioverter defibrillator implantation; 'surgeries/procedures with high risk of bleeding include: complex left-sided ablation, spinal or epidural anesthesia, lumbar diagnostic puncture, thoracic surgery, abdominal surgery, major orthopedic surgery, liver biopsy, transurethral prostate resection, and kidney biopsy. Adapted from Heidbuchel $\mathrm{H}$, Verhamme P, Alings M, et al. European Heart Rhythm Association practical guide on the use of new oral anticoagulants in patients with non-valvular atrial fibrillation. Europace. $2013,15,5,625-651$, by permission of Oxford University Press. ${ }^{53}$

Abbreviation: $\mathrm{CrCl}$, creatinine clearance. 


\section{Conclusion}

Direct oral anticoagulants have been demonstrated in Phase III clinical trials to be noninferior to warfarin in preventing stroke and systemic embolism in nonvalvular AF, with a favorable benefit-risk profile. Indeed, the incidence of $\mathrm{ICH}$ and fatal bleeding is significantly lower compared with warfarin. ESC guidelines now recommend direct oral anticoagulants over VKAs for most patients with nonvalvular AF. ${ }^{8}$

The ability of the direct oral anticoagulants to target one specific component in the coagulation cascade, together with their fast onset of action, short half-lives, and low potential for food or drug interactions, differentiates them from the VKAs. These qualities enable direct oral anticoagulants to be administered in fixed doses without routine coagulation monitoring.

Specific care protocols for individual patients will further allow physicians to maximize the efficacy of antithrombotic therapy of their patients and reduce the risk of bleeding complications when using direct oral anticoagulants.

\section{Acknowledgments}

The author would like to acknowledge Jo Luscombe for editorial support, with funding from Bayer HealthCare Pharmaceuticals and Janssen Research and Development, LLC.

\section{Disclosure}

Dr Jerome Ment has received no payment in preparation of the manuscript. The author reports no conflicts of interest in this work.

\section{References}

1. Wolf PA, Abbott RD, Kannel WB. Atrial fibrillation: a major contributor to stroke in the elderly. The Framingham Study. Arch Intern Med. 1987;147(9):1561-1564.

2. Wolf PA, Abbott RD, Kannel WB. Atrial fibrillation as an independent risk factor for stroke: the Framingham Study. Stroke. 1991;22(8):983-988.

3. Heeringa J, van der Kuip DA, Hofman A, et al. Prevalence, incidence and lifetime risk of atrial fibrillation: the Rotterdam Study. Eur Heart J. 2006;27(8):949-953.

4. Go AS, Hylek EM, Phillips KA, et al. Prevalence of diagnosed atrial fibrillation in adults: national implications for rhythm management and stroke prevention: the AnTicoagulation and Risk Factors in Atrial Fibrillation (ATRIA) Study. JAMA. 2001;285(18):2370-2375.

5. Naccarelli GV, Varker H, Lin J, Schulman KL. Increasing prevalence of atrial fibrillation and flutter in the United States. Am J Cardiol. 2009;104(11):1534-1539.

6. Jørgensen HS, Nakayama H, Reith J, Raaschou HO, Olsen TS. Acute stroke with atrial fibrillation. The Copenhagen Stroke Study. Stroke. 1996;27(10):1765-1769.

7. Lamassa M, Di Carlo A, Pracucci G, et al. Characteristics, outcome, and care of stroke associated with atrial fibrillation in Europe: data from a multicenter multinational hospital-based registry (The European Community Stroke Project). Stroke. 2001;32(2):392-398.
8. Camm AJ, Lip GY, De Caterina R, et al. 2012 focused update of the ESC Guidelines for the management of atrial fibrillation: an update of the 2010 ESC Guidelines for the management of atrial fibrillation. Developed with the special contribution of the European Heart Rhythm Association. Eur Heart J. 2012;33(21):2719-2747.

9. You JJ, Singer DE, Howard PA, et al. Antithrombotic therapy for atrial fibrillation: antithrombotic therapy and prevention of thrombosis, 9th ed: American College of Chest Physicians evidence-based clinical practice guidelines. Chest. 2012;141(2 Suppl):e531S-e575S.

10. Gage BF, van Walraven C, Pearce L, et al. Selecting patients with atrial fibrillation for anticoagulation: stroke risk stratification in patients taking aspirin. Circulation. 2004;110(16):2287-2292.

11. Fuster V, Rydén LE, Cannom DS, et al. 2011 ACCF/AHA/HRS focused updates incorporated into the ACC/AHA/ESC 2006 guidelines for the management of patients with atrial fibrillation: a report of the American College of Cardiology Foundation/American Heart Association Task Force on Practice Guidelines. Circulation. 2011;123: e269-e367.

12. Gage BF, Waterman AD, Shannon W, Boechler M, Rich MW, Radford MJ. Validation of clinical classification schemes for predicting stroke: results from the National Registry of Atrial Fibrillation. JAMA 2001;285(22):2864-2870

13. Lip GY, Nieuwlaat R, Pisters R, Lane D, Crijns H. Refining clinical risk stratification for predicting stroke and thromboembolism in atrial fibrillation using a novel risk factor based approach: the euro heart survey on atrial fibrillation. Chest. 2010;137(2):263-272.

14. Cowan C, Healicon R, Robson I, et al. The use of anticoagulants in the management of atrial fibrillation among general practices in England. Heart. 2013;99(16):1166-1172.

15. Camm AJ, Kirchhof P, Lip GY, et al. Guidelines for the management of atrial fibrillation: the task force for the management of atrial fibrillation of the European Society of Cardiology (ESC). Europace. 2010;12(10):1360-1420.

16. Hart RG, Pearce LA, Aguilar MI. Meta-analysis: antithrombotic therapy to prevent stroke in patients who have nonvalvular atrial fibrillation. Ann Intern Med. 2007;146(12):857-867.

17. Mant J, Hobbs FDR, Fletcher K, et al. Warfarin versus aspirin for stroke prevention in an elderly community population with atrial fibrillation (the Birmingham Atrial Fibrillation Treatment of the Aged Study, BAFTA): a randomised controlled trial. Lancet. 2007;370(9586): 493-503.

18. ACTIVE Writing Group of the ACTIVE Investigators. Clopidogrel plus aspirin versus oral anticoagulation for atrial fibrillation in the Atrial fibrillation Clopidogrel Trial with Irbesartan for prevention of Vascular Events (ACTIVE W): a randomised controlled trial. Lancet. 2006;367(9526):1903-1912.

19. Ansell J, Hirsh J, Hylek E, Jacobson A, Crowther M, Palareti G. Pharmacology and management of the vitamin K antagonists: American College of Chest Physicians evidence-based clinical practice guidelines (8th Edition). Chest. 2008;133(6 Suppl):160S-198S.

20. Hobbs FDR, Leach I. Challenges of stroke prevention in patients with atrial fibrillation in clinical practice. QJM. 2011;104(9):739-746.

21. Lin PJ. Reviewing the reality: why we need to change. Eur Heart $J$ Suppl. 2005;7(Suppl E):E15-E20.

22. Mavrakanas T, Bounameaux H. The potential role of new oral anticoagulants in the prevention and treatment of thromboembolism. Pharmacol Ther. 2011;130(1):46-58.

23. Eliquis ${ }^{\circledR}$ (apixaban) [Summary of Product Characteristics]. Middlesex, UK: Bristol-Myers Squibb, Pfizer; 2014. Available from: http://www ema.europa.eu/docs/en_GB/document_library/EPAR_-_Product_Information/human/002148/WC500107728.pdf. Accessed January 6, 2015.

24. Pradaxa ${ }^{\circledR}$ (dabigatran etexilate) [Summary of Product Characteristics]. Ingelheim, Germany: Boehringer Ingelheim International $\mathrm{GmbH} ; 2014$ Available from: http://www.ema.europa.eu/docs/en_GB/document_ library/EPAR_-_Product_Information/human/000829/WC500041059. pdf. Accessed January 6, 2015. 
25. Xarelto ${ }^{\circledR}$ (rivaroxaban) [Summary of Product Characteristics.] Berlin, Germany: Bayer Pharma AG; 2014. Available from: http://www.ema. europa.eu/docs/en_GB/document_library/EPAR_-_Product_Information/human/000944/WC500057108.pdf. Accessed January 6, 2015.

26. Savaysa ${ }^{\circledR}$ (edoxaban) [Prescribing Information]. Parsippany, NJ: Daiichi Sankyo Inc.; 2015. Available from: http://dsi.com/prescribinginformation-portlet $/$ getPIContent?productName=Savaysa\&inline=true. Accessed January 12, 2015.

27. January CT, Wann LS, Alpert JS, et al. 2014 AHA/ACC/HRS guideline for the management of patients with atrial fibrillation: a report of the American College of Cardiology/American Heart Association Task Force on practice guidelines and the Heart Rhythm Society. J Am Coll Cardiol. 2014;64(21):e1-e76.

28. Eriksson BI, Quinlan DJ, Eikelboom JW. Novel oral Factor Xa and thrombin inhibitors in the management of thromboembolism. Annu Rev Med. 2011;62:41-57.

29. Ansell J. Warfarin versus new agents: interpreting the data. Hematology Am Soc Hematol Educ Program. 2010;2010:221-228.

30. Harder S. Renal profiles of anticoagulants. J Clin Pharmacol. 2012; 52(7):964-975.

31. Verma AK, Brighton TA. The direct factor Xa inhibitor rivaroxaban. Med J Aust. 2009;190(7):379-383.

32. Connolly SJ, Ezekowitz MD, Yusuf S, et al. Dabigatran versus warfarin in patients with atrial fibrillation. $N$ Engl J Med. 2009;361(12): 1139-1151.

33. Patel MR, Mahaffey KW, Garg J, et al. Rivaroxaban versus warfarin in nonvalvular atrial fibrillation. $N$ Engl J Med. 2011;365(10):883-891.

34. Granger CB, Alexander JH, McMurray JJ, et al. Apixaban versus warfarin in patients with atrial fibrillation. $N$ Engl J Med. 2011;365(11): 981-992.

35. Connolly SJ, Eikelboom J, Joyner C, et al. Apixaban in patients with atrial fibrillation. N Engl J Med. 2011;364(9):806-817.

36. Giugliano RP, Ruff CT, Braunwald E, et al. Edoxaban versus warfarin in patients with atrial fibrillation. $N$ Engl J Med. 2013;369(22): 2093-2104.

37. Connolly SJ, Wallentin L, Yusuf S. Additional events in the RE-LY trial. N Engl J Med. 2014;371:1464-1465.

38. Connolly SJ, Ezekowitz MD, Yusuf S, Reilly PA, Wallentin L. Newly identified events in the RE-LY trial. N Engl J Med. 2010;363(19): 1875-1876.

39. Steiner T, Rosand J, Diringer M. Intracerebral hemorrhage associated with oral anticoagulant therapy: current practices and unresolved questions. Stroke. 2006;37(1):256-262.

40. Healey JS, Eikelboom J, Douketis J, et al. Periprocedural bleeding and thromboembolic events with dabigatran compared with warfarin: results from the randomized evaluation of long-term anticoagulation therapy (RE-LY) randomized trial. Circulation. 2012;126(3):343-348.

41. Eikelboom JW, Wallentin L, Connolly SJ, et al. Risk of bleeding with 2 doses of dabigatran compared with warfarin in older and younger patients with atrial fibrillation: an analysis of the randomized evaluation of long-term anticoagulant therapy (RE-LY) trial. Circulation. 2011;123:2363-2372.

42. Ogata K, Mendell-Harary J, Tachibana M, et al. Clinical safety, tolerability, pharmacokinetics, and pharmacodynamics of the novel Factor Xa inhibitor edoxaban in healthy volunteers. J Clin Pharmacol. 2010; 50(7):743-753.

43. Fox KAA, Piccini JP, Wojdyla D, et al. Prevention of stroke and systemic embolism with rivaroxaban compared with warfarin in patients with non-valvular atrial fibrillation and moderate renal impairment. Eur Heart J. 2011;32(19):2387-2394.

44. Sardar P, Chatterjee S, Herzog E, Nairooz R, Mukherjee D, Halperin JL. Novel oral anticoagulants in patients with renal insufficiency: a metaanalysis of randomized trials. Can J Cardiol. 2014;30(8):888-897.

45. Diener HC, Connolly SJ, Ezekowitz MD, et al. Dabigatran compared with warfarin in patients with atrial fibrillation and previous transient ischaemic attack or stroke: a subgroup analysis of the RE-LY trial. Lancet Neurol. 2010;9(12):1157-1163.
46. Hankey GJ, Patel MR, Stevens SR, et al. Rivaroxaban compared with warfarin in patients with atrial fibrillation and previous stroke or transient ischaemic attack: a subgroup analysis of ROCKET AF. Lancet Neurol. 2012;11(4):315-322.

47. Easton JD, Lopes RD, Bahit MC, et al. Apixaban compared with warfarin in patients with atrial fibrillation and previous stroke or transient ischaemic attack: a subgroup analysis of the ARISTOTLE trial. Lancet Neurol. 2012;11(6):503-511.

48. Ezekowitz MD, Connolly S, Parekh A, et al. Rationale and design of RE-LY: randomized evaluation of long-term anticoagulant therapy, warfarin, compared with dabigatran. Am Heart J. 2009;157(5):805-810.

49. ROCKET AF Study Investigators. Rivaroxaban - once-daily, oral, direct Factor Xa inhibition - compared with vitamin K antagonism for prevention of stroke and embolism trial in atrial fibrillation: rationale and design of the ROCKET AF Study. Am Heart J. 2010;159:340-347.

50. Lopes RD, Alexander JH, Al-Khatib SM, et al. Apixaban for Reduction In Stroke and Other ThromboemboLic Events in Atrial Fibrillation (ARISTOTLE) trial: design and rationale. Am Heart J. 2010;159(3): 331-339.

51. Sandercock PAG, Counsell C, Kamal AK. Anticoagulants for acute ischaemic stroke. Cochrane Database Syst Rev. 2008;(4):CD000024. Available from: http://dx.doi.org/10.1002/14651858.CD000024.pub3. Accessed April 18, 2013.

52. Hankey GJ. Anticoagulant therapy for patients with ischaemic stroke. Nat Rev Neurol. 2012;8(6):319-328.

53. Heidbuchel H, Verhamme P, Alings M, et al. European Heart Rhythm Association practical guide on the use of new oral anticoagulants in patients with non-valvular atrial fibrillation. Europace. 2013;15(5): 625-651.

54. The European Stroke Organisation (ESO) Executive Committee, ESO Writing Committee. Guidelines for management of ischaemic stroke and transient ischaemic attack 2008. Cerebrovasc Dis. 2008;25(5): 457-507.

55. Hankey GJ, Jamrozik K, Broadhurst RJ, et al. Long-term risk of first recurrent stroke in the Perth Community Stroke Study. Stroke. 1998;29(12):2491-2500.

56. Arnold AZ, Mick MJ, Mazurek RP, Loop FD, Trohman RG. Role of prophylactic anticoagulation for direct current cardioversion in patients with atrial fibrillation or atrial flutter. J Am Coll Cardiol. 1992;19(4): 851-855.

57. Cappato R, Ezekowitz MD, Klein AL, et al. Rivaroxaban vs vitamin $\mathrm{K}$ antagonists for cardioversion in atrial fibrillation. Eur Heart $J$. 2014;35(47):3346-3355.

58. Piccini JP, Stevens SR, Lokhnygina Y, et al. Outcomes following cardioversion and atrial fibrillation ablation in patients treated with rivaroxaban and warfarin in the ROCKET AF trial. J Am Coll Cardiol. 2013;61(19):1998-2006.

59. Nagarakanti R, Ezekowitz MD, Oldgren J, et al. Dabigatran versus warfarin in patients with atrial fibrillation: an analysis of patients undergoing cardioversion. Circulation. 2011;123(2):131-136.

60. Flaker G, Lopes RD, Al Khatib SM, et al. Efficacy and safety of apixaban in patients after cardioversion for atrial fibrillation: insights from the ARISTOTLE Trial (Apixaban for Reduction in Stroke and Other Thromboembolic Events in Atrial Fibrillation). J Am Coll Cardiol. 2014;63(11):1082-1087.

61. Pfizer. Study of the blood thinner, apixaban, for patients who have an abnormal heart rhythm (atrial fibrillation) and expected to have treatment to put them back into a normal heart rhythm (cardioversion) (EMANATE). Available from: http://clinicaltrials. gov/show/NCT02100228. NLM identifier: NCT02100228. Accessed November 10, 2014.

62. Hamm CW, Bassand JP, Agewall S, et al. ESC guidelines for the management of acute coronary syndromes in patients presenting without persistent ST-segment elevation: the task force for the management of Acute Coronary Syndromes (ACS) in patients presenting without persistent ST-segment elevation of the European Society of Cardiology (ESC). Eur Heart J. 2011;32:2999-3054. 
63. Steg PG, James SK, Atar D, et al. ESC guidelines for the management of acute myocardial infarction in patients presenting with ST-segment elevation: the task force on the management of ST-segment elevation acute myocardial infarction of the European Society of Cardiology (ESC). Eur Heart J. 2012;33(20):2569-2619.

64. Lip GYH, Windecker S, Huber K, et al. Management of antithrombotic therapy in atrial fibrillation patients presenting with acute coronary syndrome and/or undergoing percutaneous coronary or valve interventions: a joint consensus document of the European Society of Cardiology Working Group on Thrombosis, European Heart Rhythm Association (EHRA), European Association of Percutaneous Cardiovascular Interventions (EAPCI) and European Association of Acute Cardiac Care (ACCA) endorsed by the Heart Rhythm Society (HRS) and Asia-Pacific Heart Rhythm Society (APHRS). Eur Heart J. 2014;35(45):3155-3179.

65. Mega JL, Braunwald E, Mohanavelu S, et al. Rivaroxaban versus placebo in patients with acute coronary syndromes (ATLAS ACS-TIMI 46): a randomised, double-blind, phase II trial. Lancet. 2009;374:29-38.

66. Alexander JH, Lopes RD, James S, et al. Apixaban with antiplatelet therapy after acute coronary syndrome. $N$ Engl J Med. 2011;365(8): 699-708.

67. Dans AL, Connolly SJ, Wallentin L, et al. Concomitant use of antiplatelet therapy with dabigatran or warfarin in the Randomized Evaluation of Long-Term Anticoagulation Therapy (RE-LY) trial. Circulation. 2013;127(5):634-640.

68. Oldgren J, Budaj A, Granger CB, et al. Dabigatran vs placebo in patients with acute coronary syndromes on dual antiplatelet therapy: a randomized, double-blind, phase II trial. Eur Heart J. 2011;32(22): 2781-2789.

69. Hansen ML, Sørensen R, Clausen MT, et al. Risk of bleeding with single, dual, or triple therapy with warfarin, aspirin, and clopidogrel in patients with atrial fibrillation. Arch Intern Med. 2010;170(16):1433-1441.

70. Janssen Scientific Affairs LLC. A study exploring two strategies of rivaroxaban (JNJ39039039; BAY-59-7939) and one of oral vitamin K antagonist in patients with atrial fibrillation who undergo percutaneous coronary intervention (PIONEER AF-PCI). Available from: http://clinicaltrials.gov/ct2/show/NCT01830543. NLM identifier: NCT01830543. Accessed November 10, 2014.

71. Boehringer Ingelheim. Evaluation of dual therapy with dabigatran vs triple therapy with warfarin in patients with AF that undergo a PCI with stenting (REDUAL-PCI). Available from: https://clinicaltrials.gov/ ct2/show/NCT02164864. NLM identifier: NCT02164864. Accessed September 11, 2014.

72. Peacock WF, Gearhart MM, Mills RM. Emergency management of bleeding associated with old and new oral anticoagulants. Clin Cardiol. 2012;35(12):730-737.

73. Crowther MA, Warkentin TE. Bleeding risk and the management of bleeding complications in patients undergoing anticoagulant therapy: focus on new anticoagulant agents. Blood. 2008;111(10):4871-4879.

74. Kazmi RS, Lwaleed BA. New anticoagulants: how to deal with treatment failure and bleeding complications. Br J Clin Pharmacol. 2011;72(4):593-603.

75. Portola Pharmaceuticals. A study in older subjects to evaluate the safety and ability of andexanet alfa to reverse the anticoagulation effect of rivaroxaban. Available from: http://clinicaltrials.gov/ct2/show/NCT02220725. NLM identifier: NCT02220725. Accessed November 10, 2014.

76. Portola Pharmaceuticals. A study in older subjects to evaluate the safety and ability of andexanet alfa to reverse the anticoagulation effect of apixaban. Available from: http://clinicaltrials.gov/ct2/show/NCT02207725. NLM identifier: NCT02207725. Accessed November 10, 2014

77. Boehringer Ingelheim. Reversal of dabigatran anticoagulant effect with idarucizumab. Available from: http://clinicaltrials.gov/ct2/ show/NCT02104947. NLM identifier: NCT02104947. Accessed November 10, 2014.

78. Marlu R, Hodaj E, Paris A, Albaladejo P, Crackowski JL, Pernod G. Effect of non-specific reversal agents on anticoagulant activity of dabigatran and rivaroxaban. A randomised crossover ex vivo study in healthy volunteers. Thromb Haemost. 2012;108(2):217-224.
79. Khoo TL, Weatherburn C, Kershaw G, Reddel CJ, Curnow J, Dunkley S. The use of FEIBA(R) in the correction of coagulation abnormalities induced by dabigatran. Int J Lab Hematol. 2013;35(2):222-224.

80. Körber MK, Langer E, Ziemer S, Perzborn E, Gericke C, von Heymann C. Measurement and reversal of prophylactic and therapeutic peak levels of rivaroxaban: an in vitro study. Clin Appl Thromb Hemost. 2014;20(7):735-740.

81. Pragst I, Zeitler SH, Doerr B, et al. Reversal of dabigatran anticoagulation by prothrombin complex concentrate (Beriplex $\mathrm{P} / \mathrm{N})$ in a rabbit model. J Thromb Haemost. 2012;10(9):1841-1848.

82. Godier A, Miclot A, Le Bonniec B, et al. Evaluation of prothrombin complex concentrate and recombinant activated factor VII to reverse rivaroxaban in a rabbit model. Anesthesiology. 2012;116(1):94-102.

83. Lambourne MD, Eltringham-Smith LJ, Gataiance S, Arnold DM, Crowther MA, Sheffield WP. Prothrombin complex concentrates reduce blood loss in murine coagulopathy induced by warfarin, but not in that induced by dabigatran etexilate. J Thromb Haemost. 2012;10(9):1830-1840.

84. Perzborn E, Gruber A, Tinel H, et al. Reversal of rivaroxaban anticoagulation by haemostatic agents in rats and primates. Thromb Haemost. 2013;110(1):162-172.

85. Martin AC, Le Bonniec B, Fischer AM, et al. Evaluation of recombinant activated factor VII, prothrombin complex concentrate, and fibrinogen concentrate to reverse apixaban in a rabbit model of bleeding and thrombosis. Int J Cardiol. 2013;168(4):4228-4233.

86. Zhou W, Zorn M, Nawroth P, et al. Hemostatic therapy in experimental intracerebral hemorrhage associated with rivaroxaban. Stroke. 2013;44(3):771-778.

87. Eerenberg ES, Kamphuisen PW, Sijpkens MK, Meijers JC, Buller HR, Levi M. Reversal of rivaroxaban and dabigatran by prothrombin complex concentrate: a randomized, placebo-controlled, crossover study in healthy subjects. Circulation. 2011;124(14):1573-1579.

88. Levi M, Moore KT, Castillejos CF, et al. Comparison of three- and four-factor prothrombin complex concentrates on the anticoagulant effects of rivaroxaban in healthy volunteers. $J$ Thromb Haemost. 2014;12(9):1428-1436.

89. Piccini JP, Garg J, Patel MR, et al. Management of major bleeding events in patients treated with rivaroxaban vs warfarin: results from the ROCKET AF trial. Eur Heart J. 2014;35(28):1873-1880.

90. Beyer-Westendorf J, Forster K, Pannach S, et al. Rates, management, and outcome of rivaroxaban bleeding in daily care: results from the Dresden NOAC registry. Blood. 2014;124(6):955-962.

91. Schulman S, Crowther MA. How I treat with anticoagulants in 2012: new and old anticoagulants, and when and how to switch. Blood. 2012; 119(13):3016-3023.

92. Kearon C, Hirsh J. Management of anticoagulation before and after elective surgery. $N$ Engl J Med. 1997;336(21):1506-1511.

93. Hirsh J, Fuster V, Ansell J, Halperin JL. American Heart Association/ American College of Cardiology Foundation guide to warfarin therapy. Circulation. 2003;107(12):1692-1711.

94. Stampfuss J, Kubitza D, Becka M, Mueck W. The effect of food on the absorption and pharmacokinetics of rivaroxaban. Int J Clin Pharmacol Ther. 2013;51(7):549-561.

95. Matsushima N, Lee F, Sato T, Weiss D, Mendell J. Bioavailability and safety of the Factor Xa inhibitor edoxaban and the effects of quinidine in healthy subjects. Clin Pharm Drug Dev. 2013;2(4):358-366.

96. Mendell J, Zahir H, Matsushima N, et al. Drug-drug interaction studies of cardiovascular drugs involving P-glycoprotein, an efflux transporter, on the pharmacokinetics of edoxaban, an oral Factor Xa inhibitor. Am J Cardiovasc Drugs. 2013;13(5):331-342.

97. Eikelboom JW, Connolly SJ, Brueckmann M, et al. Dabigatran versus warfarin in patients with mechanical heart valves. $N$ Engl J Med. 2013;369(13):1206-1214. 


\section{Publish your work in this journal}

Vascular Health and Risk Management is an international, peerreviewed journal of therapeutics and risk management, focusing on concise rapid reporting of clinical studies on the processes involved in the maintenance of vascular health; the monitoring, prevention and treatment of vascular disease and its sequelae; and the involvement of

metabolic disorders, particularly diabetes. This journal is indexed on PubMed Central and MedLine. The manuscript management system is completely online and includes a very quick and fair peer-review system, which is all easy to use. Visit http://www.dovepress.com/ testimonials.php to read real quotes from published authors.

Submit your manuscript here: http://www.dovepress.com/vascular-health-and-risk-management-journal 